\title{
Metabolic Clearance Rate of \\ Radioiodinated Human Growth Hormone in Man
}

\author{
Donald P. Cameron, Henry G. Burger, Kevin J. Catt, and \\ Alison Doig \\ From the Medical Research Center and the Monash University Department \\ of Medicine, Prince Henry's Hospital, Melbourne, Victoria, Australia, 3004, \\ and the Department of Statistics, University of Melbourne, Melbourne, \\ Victoria, Australia, 3052
}

\begin{abstract}
A B STRACT The nature of the disappearance of radioiodinated human growth hormone $(\mathrm{HGH})$ from plasma has been reexamined. The metabolic clearance rate $(\mathrm{MCR})$ was determined both from single injection and constant infusion studies. After single injection of highly purified radioiodinated $\mathrm{HGH}$, the disappearance curve remained multiexponential during the period of study $(4 \mathrm{hr})$. The shape of the curve was independent of the growth hormone preparation used. Similar disappearance curves were obtained with unlabeled $\mathrm{HGH}$.

MCR values calculated from constant infusion studies were $203 \pm 7.8$ liters/day per $\mathrm{m}^{2}$ and values derived from single injection studies agreed closely with this.

The multiexponential nature of the disappearance curve does not permit meaningful calculation of volume of distribution or half-time of disappearance.
\end{abstract}

\section{INTRODUCTION}

The disappearance from plasma of a rapidly administered intravenous dose of isotopically labeled human growth hormone $(\mathrm{HGH})$ has been investigated by a number of workers, but the data derived from these studies is somewhat conflicting. Parker, Utiger, and Daughaday (1) and Boucher (2) have reported that plasma disappearance curves can be described by a single exponential function, but other workers $(3,4)$ have described a more complex situation in which a rapid early disappearance is followed by a much slower later phase. While values for half-times of disappearance have been estimated from these data, no estimates of

A preliminary report of this work was presented at the Third International Congress of Endocrinology, Mexico City, 30 June-5 July, 1968.

Received for publication 3 October 1968 and in revised form 10 May 1969. metabolic clearance rate (MCR) have been published, nor have studies been reported in which the technique of constant infusion to equilibrium has been utilized to derive MCR.

In the present study the nature of the disappearance of radioiodinated $\mathrm{HGH}$ from plasma has been further examined, and the data obtained have been used to calculate MCR. These values have been compared with estimates of MCR derived from constant infusion studies.

\section{METHODS}

HGH preparation. The majority of these experiments were performed with $\mathrm{HGH}$ of biological activity $1.5 \mathrm{U} / \mathrm{mg}$ prepared by a modification (5) of the Raben procedure (6) (HGH R) and further purified by gel filtration on a Sephadex G100 column. The peak tube from the growth hormone fraction was used for iodination. Several experiments were performed with $\mathrm{HGH}$ prepared by the methods of Wallace and Ferguson (7) (HGH F), ${ }^{1}$ Wilhelmi (8), and Tashjian, Armen, Levine, and Wilhelmi (9) (HGH W). ${ }^{2}$

Iodination. Iodination of $\mathrm{HGH}$ with ${ }^{125} \mathrm{I}$ or ${ }^{131} \mathrm{I}$ was performed by a modification (10) of the chloramine- $T$ method of Greenwood, Hunter, and Glover (11) employing radioiodine obtained from The Radiochemical Center, Amersham, Buckinghamshire, U. K. Reaction conditions were chosen to achieve a specific activity of between $3 \mu \mathrm{c}$ and $20 \mu \mathrm{c} / \mu \mathrm{g}$. The iodinated hormone was purified by gel filtration on a Sephadex G75 column, fractions of $1.5 \mathrm{ml}$ being collected into $0.5 \mathrm{ml}$ of $5 \%$ human serum albumin. Individual or two consecutive fractions from the growth hormone peak were prepared for administration.

Preparation and administration. Sterilization was carried out by Millipore filtration $(0.22 \mu$ filter and the samples tested for sterility by standard bacteriological techniques. The tracer was stored at $4^{\circ} \mathrm{C}$ and was used within 1 wk of iodination. Examination of all preparations by chromato-

${ }^{1}$ Gift of Dr. K. A. Ferguson, CSIRO Division of Animal Physiology, Prospect, N. S. W., Australia.

${ }^{2}$ Gift of Dr. A. E. Wilhelmi, Emory University, Atlanta, Ga. Batch No. NIH GH HS 1004C. 
electrophoresis immediately before administration showed that labeling damage was $4-6 \%$. Immunological reactivity determined on a number of occasions by double antibody precipitation (see below) showed that $90-98 \%$ of the labeled material could be precipitated by this means.

$40-150 \mu \mathrm{c}(4-30 \mu \mathrm{g})$ of $\mathrm{HGH}^{125} \mathrm{I}$ or $\mathrm{HGH}_{-}{ }^{131} \mathrm{I}$ was administered intravenously to each subject. For single injection studies the injection was made into an antecubital vein and the cannula flushed with saline. Blood was sampled periodically for $4 \mathrm{hr}$ from the opposite antecubital vein. In constant infusion studies infusion was by means of a Harvard constant infusion pump at $11.2-11.4 \mathrm{ml} / \mathrm{hr}$ without a prior loading dose. The constancy of administration of labeled $\mathrm{HGH}$ was carefully established by demonstrating constant delivery of radioactivity from the connecting tubing at the beginning and end of several infusions. Essentially, constant plasma levels of iodinated hormone were obtained by $2 \frac{1}{2}-3 \mathrm{hr}$ and sampling was continued for $4 \mathrm{hr}$.

Blood samples were taken into tubes containing $100 \mathrm{U}$ sodium heparin, immediately centrifuged, and the plasma separated. Procedures for the analysis of iodinated hormone were carried out on the day the specimens were obtained.
Plasma for radioimmunoassay was stored at $-16^{\circ} \mathrm{C}$ till assay was performed.

Analysis of plasma hormone. The total radioactivity of duplicate $0.5 \mathrm{ml}$ samples of plasma was determined in an automatic gamma counter (Nuclear-Chicago Corporation,

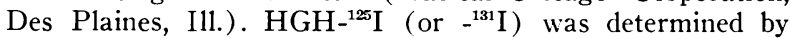
the following methods.

(a) Precipitation with an equal vo:ume of cold $10 \%$ trichloracetic acid (TCA).

(b) Chromatoelectrophoresis on Whatman $3 \mathrm{MC}$ or Whatman DEAE chromatography paper. The strips used were $3.2 \mathrm{~cm}$ in width. When the $3 \mathrm{MC}$ paper was used $10 \mu \mathrm{l}$ of plasma were applied to each strip and electrophoresis was carried out at $5^{\circ} \mathrm{C}$ in $0.05 \mathrm{~m}$ barbitone buffer $\mathrm{pH} 8.6$, with a current of 6 ma per strip until the plasma protein front had moved $7.5 \mathrm{~cm}$ (usually $1.25 \mathrm{hr}$ ). After the separation conditions had been established the strips were divided midway between the center of the protein front and the origin and again just distal to the protein front. This enabled the separation of growth hormone, as material remaining at the origin, from damaged components that moved with the serum proteins, and from iodide moving in advance of

TABLE I

Metabolic Clearance Rate

\begin{tabular}{|c|c|c|c|c|c|c|c|c|}
\hline \multirow[b]{2}{*}{ Subject } & \multirow[b]{2}{*}{ Sex } & \multirow[b]{2}{*}{ Age } & \multirow[b]{2}{*}{ Clinical state } & \multirow[b]{2}{*}{ Surface area } & \multirow{2}{*}{$\begin{array}{l}\text { HGH } \\
\text { prepa- } \\
\text { ration }\end{array}$} & \multicolumn{3}{|c|}{ MCR } \\
\hline & & & & & & SAAM 2 & SAAM 3 & Planimetry \\
\hline & & $y r$ & & $m^{2}$ & & & iter/day per $m^{2}$ & \\
\hline \multicolumn{9}{|c|}{ Single injection } \\
\hline V. R. & $\mathrm{F}$ & 21 & Normal & 1.53 & $\mathrm{R}$ & 292 & 260 & 212 \\
\hline H. B. & M & 34 & Normal & 2.02 & $\mathrm{R}$ & 224 & 127 & 168 \\
\hline H. B. & M & 34 & Normal & 2.02 & $\mathrm{~F}$ & 207 & $194^{*}$ & 158 \\
\hline P. M. & $M$ & 30 & Normal & 1.86 & $\mathrm{~F}$ & 223 & 208 & 171 \\
\hline D. C. & M & 29 & Normal & 1.8 & $\mathrm{R}$ & 204 & 126 & 172 \\
\hline D. C. & M & 29 & Normal & 1.8 & $W$ & 226 & $202^{*}$ & 168 \\
\hline P. D. & $\mathrm{F}$ & 28 & Normal & 1.49 & $\mathrm{R}$ & 250 & $224^{*}$ & 197 \\
\hline J. D. & $\mathrm{F}$ & 25 & Normal & 1.53 & $\mathrm{R}$ & 241 & $224^{*}$ & 179 \\
\hline J. K. & $\mathrm{F}$ & 22 & Normal & 1.41 & $\mathrm{R}$ & 209 & $210^{*}$ & 219 \\
\hline A. F. & M & 21 & Normal & 1.86 & $\mathrm{~F}$ & 230 & 206 & 180 \\
\hline J. A. & M & 21 & Normal & 1.87 & $W$ & 271 & 147 & 232 \\
\hline C. M. & M & 30 & $\begin{array}{l}\text { Fractured } \\
\text { femur }\end{array}$ & 1.59 & $\mathrm{R}$ & 197 & $156^{*}$ & 155 \\
\hline \multirow[t]{4}{*}{ J. C. } & M & 58 & Ca prostate & 1.97 & W & 293 & $274^{*}$ & 214 \\
\hline & & & Mean $\pm \mathrm{SEM}$ & $1.75 \pm 0.045$ & & $242 \pm 9.5$ & $196 \pm 12.9$ & $188 \pm 6.8$ \\
\hline & & & & & & \multicolumn{3}{|c|}{$\mathrm{MCR}$} \\
\hline & & & & & & \multicolumn{3}{|c|}{ liter/day per $m^{2}$} \\
\hline \multicolumn{9}{|c|}{ Constant infusion } \\
\hline S. G. & $\mathrm{F}$ & 56 & Schizophrenia & 1.58 & $\mathrm{R}$ & \multicolumn{3}{|c|}{211} \\
\hline M. E. & $\mathrm{F}$ & 39 & Normal & 1.65 & $\mathrm{R}$ & \multicolumn{3}{|c|}{196} \\
\hline J. D. & $\mathrm{F}$ & 25 & Normal & 1.53 & $\mathrm{R}$ & \multicolumn{3}{|c|}{211} \\
\hline P. D. & $\mathrm{F}$ & 28 & Normal & 1.49 & $\mathrm{R}$ & \multicolumn{3}{|c|}{176} \\
\hline J. K. & $\mathrm{F}$ & 22 & Normal & 1.41 & $\mathrm{R}$ & \multicolumn{3}{|c|}{181} \\
\hline J. D. & M & 22 & Normal & 1.83 & $\mathrm{R}$ & \multicolumn{3}{|c|}{236} \\
\hline \multirow[t]{2}{*}{ J. B. } & M & 23 & $\begin{array}{l}\text { Fractured } \\
\text { patella }\end{array}$ & 1.83 & $\mathrm{R}$ & \multicolumn{3}{|c|}{211} \\
\hline & & & Mean \pm SEM & & & \multicolumn{3}{|c|}{$203 \pm 7.8$} \\
\hline
\end{tabular}

* Indicates that the fit by the sum of three exponential functions is significantly better than that by the sum of two $(P<0.05$ ). 


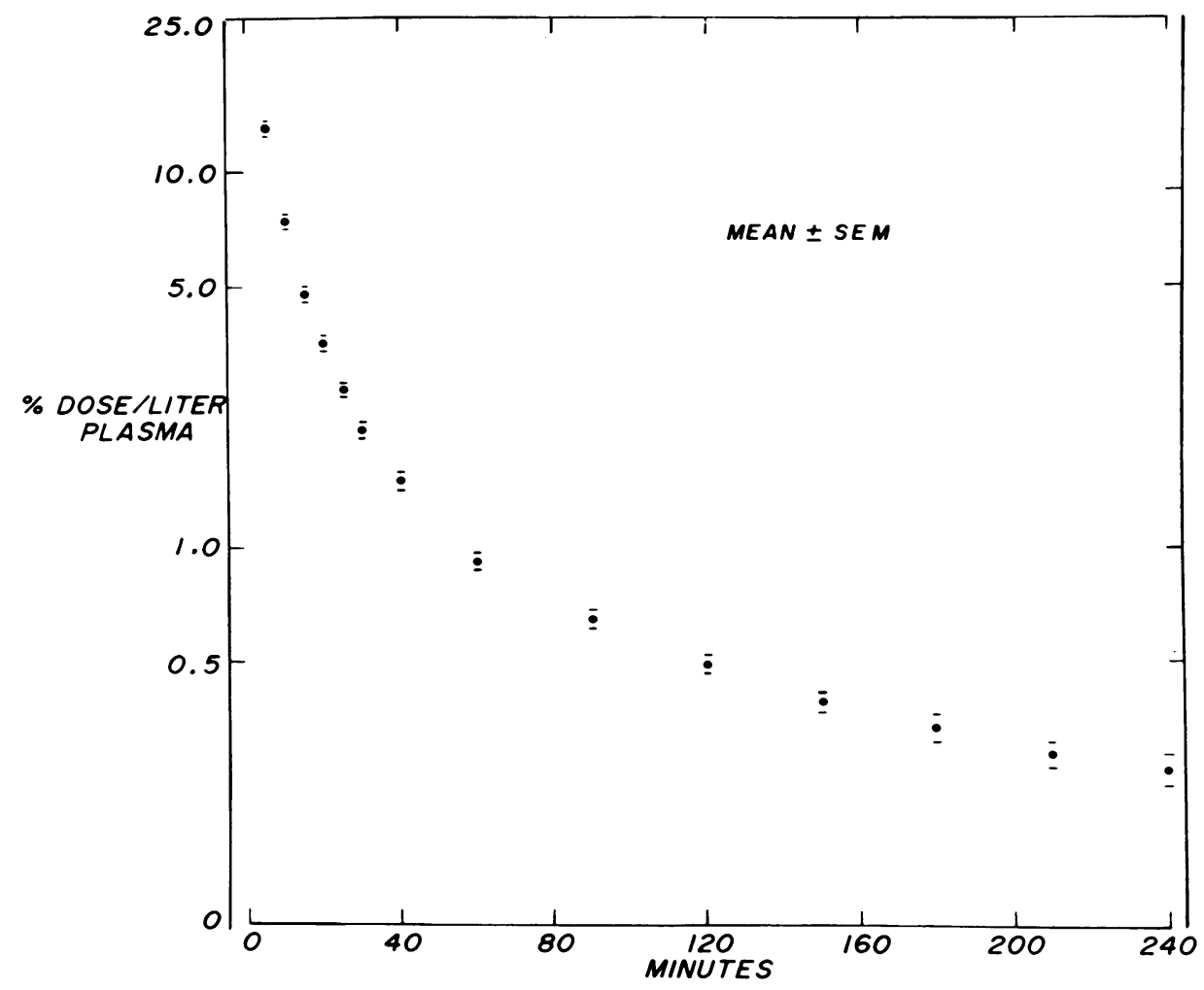

FIGURE 1 Disappearance of radioiodinated $\mathrm{HGH}$ from plasma plotted semilogarithmically. Each point represents the mean \pm SEM of values obtained by chromatoelectrophoresis in 13 studies. It can be seen that no part of the curve is linear. Samples for analysis were obtained at $5,10,15,20,25,30,40,60,90,120,150,180,210$, and $240 \mathrm{~min}$ after injection.

the serum proteins. When DEAE paper was used $200 \mu 1$ of plasma were applied to each strip and electrophoresis was performed at $5^{\circ} \mathrm{C}$ in $0.1 \mathrm{M}$ barbitone buffer $\mathrm{pH} 8.6$ with a current of 4 ma per strip until the plasma protein front had moved $7.5 \mathrm{~cm}$. The strips were divided midway between the center of the protein front and the origin. It was not possible in this system clearly to separate iodide from damaged components. With $3 \mathrm{MC}$ paper 10 strips were pooled for counting and with DEAE paper 3-5 strips.

(c) Immunoprecipitation was performed by means of a double antibody system. Rabbit antihuman growth hormone gamma globulin in a final dilution of $1: 200$ was incubated overnight at room temperature with $0.5 \mathrm{ml}$ aliquots of plasma. Sheep or goat anti-rabbit gamma globulin ${ }^{3}$ at a final dilution of $1: 4$ and $1: 8$, respectively, was then added and incubated overnight at $4^{\circ} \mathrm{C}$. The plasma was centrifuged, the supernatant aspirated, and the precipitate counted. Unlabeled HGH was assayed by radioimmunoassay using the solid-phase techniques of Catt, Niall, and Tregear (12) and Catt and Tregear (13). All specimens from one subject were run in a single assay.

Subjects studied. The clinical details of subjects are shown in Table I. All were volunteers from whom informed consent had been obtained and all were given 10 drops of Lugol's iodine solution at 8 -hr intervals for at least $24 \mathrm{hr}$ before the study.

${ }^{3}$ Gift of Dr. Struan Sutherland, Commonwealth Serum Laboratories, Parkville, Victoria, Australia.
Calculations. For all calculations of MCR, the administered radioactivity and the values for iodinated HGP in plasma are those obtained from chromatoelectrophoretic analysis. Radioactive HGH was calculated as the product of the total radioactivity in the sample multiplied by the percentage remaining at the origin in the chromatoelectrophoretic system. The precision of this method was checked by performing 10 estimations at selected times. The coefficient of variation varied from $2 \%$ at $10 \mathrm{~min}$ to $12 \%$ at $240 \mathrm{~min}$.

Metabolic clearance rate, defined as the volume of plasma completely and irreversibly cleared of hormone per unit time, was derived from both single injection and constant infusion studies. As discussed by Tait and Burstein (14), a general expression for MCR is obtained by dividing the total administered dose of a labeled hormone by the integrated plasma radioactivity: $\mathrm{MCR}$ equals $\mathrm{R} / \boldsymbol{S}_{0}{ }^{\alpha} \mathbf{x}^{\prime} \mathrm{dt}$ where $\mathrm{R}$ equals total administered dose and $\mathrm{x}^{\prime}$ equals concentration of labeled hormone in plasma.

Single injection studies. Two procedures were used for the analysis of the data obtained: (a) Planimetry, the area under the disappearance curve was measured after extrapolation of the decay line to the time axis. (b) Computer analysis of the disappearance curve using the SAAM 23 program (15) to describe the experimental data by the sum of two and three exponential functions. As discussed by Tait (16), after single injection, when the disappearance curve is described by the sum of two exponentials $x^{\prime}=A^{\prime} e^{-\alpha t}+B^{\prime} e^{-\beta t}, M C R$ 


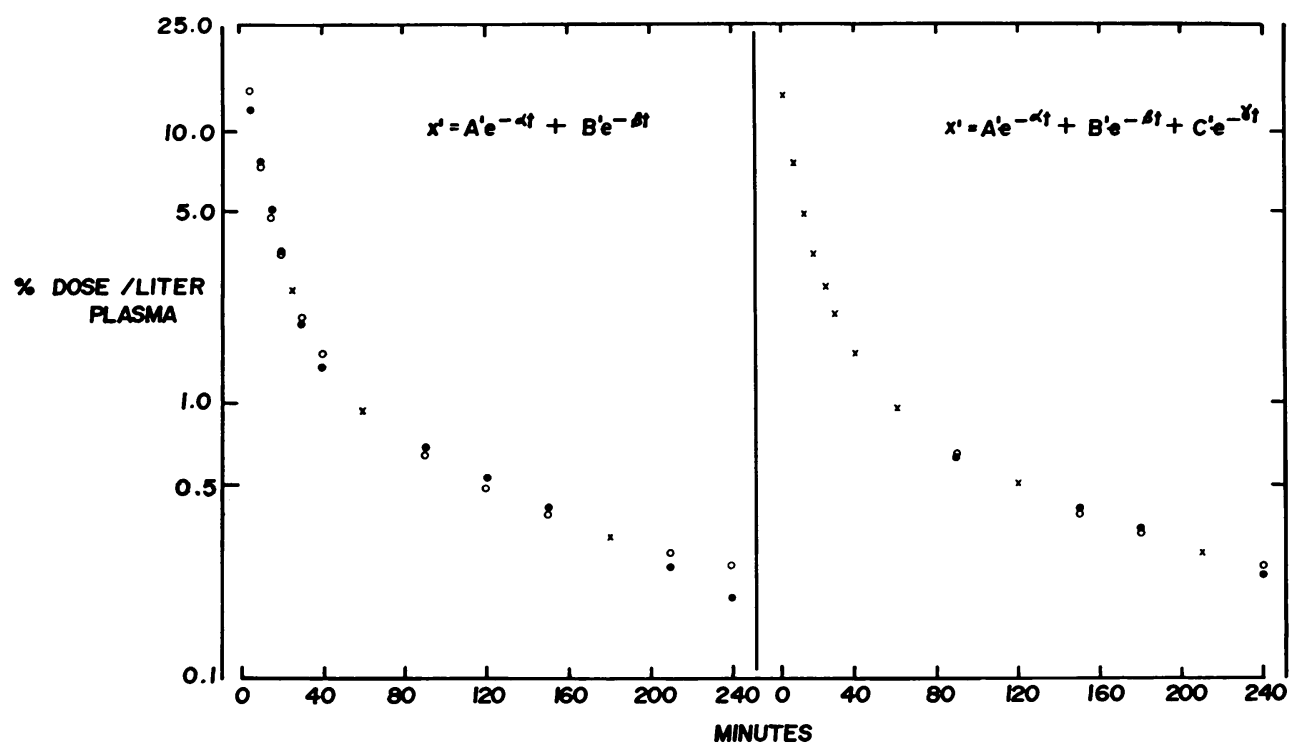

Figure 2 Comparison of the experimental $(O)$ and computer predicted ( $\bullet$ ) disappearance curves for the mean values in 13 studies. $\mathrm{X}$ signifies agreement between observed and predicted values.

$=\mathrm{R} \cdot \frac{1}{\frac{\mathrm{A}^{\prime}}{\alpha}+\frac{\mathrm{B}^{\prime}}{\beta}}$ and when three exponentials $\mathrm{x}^{\prime}=\mathrm{A}^{\prime} \mathrm{e}^{-\alpha \mathrm{t}}$

$+\mathrm{B}^{\prime} \mathrm{e}^{-\beta \mathrm{t}}+\mathrm{C}^{\prime} \mathrm{e}^{-\gamma \mathrm{t}}, \mathrm{MCR}=\mathrm{R} \cdot \frac{1}{\frac{\mathrm{A}^{\prime}}{\alpha}+\frac{\mathrm{B}^{\prime}}{\beta}+\frac{\mathrm{C}^{\prime}}{\gamma}}$ where $\mathrm{x}^{\prime}$ equals

plasma radioactive concentration $\mathrm{R}$ equals total administered radioactivity and $\mathrm{A}^{\prime}, \mathrm{B}^{\prime}, \mathrm{C}^{\prime}, \alpha, \beta$, and $\gamma$ are the parameters of the exponential functions which describe the disappearance curves.

Constant infusion studies. The calculation of MCR using this technique is independent of the number of compartments necessary to describe the system $(14,16)$. Once a constant plasma level has been achieved metabolic clearance can be calculated from the expression MCR equals $r / c$ were $r$ is the infusion rate of hormone in cpm per day and $c$ is the stable plasma level of labeled hormone in cpm per liter.

\section{RESULTS}

\section{Single injection studies}

Iodinated $H G H$. The disappearance curve of iodinated HGH given by a single intravenous injection is shown in Fig. 1. It is apparent that, in spite of the semilog transformation, the data remain curvilinear and must be described by the sum of at least two and probably several exponential functions.

Fig. 2 shows a comparison of the mean experimental points for the 13 subjects with the theoretical points obtained by computer analysis. The fit when the sum of three exponentials is used to describe the curve is very close and significantly better than that for two exponentials.
In seven studies performed with $\mathrm{HGH}$ R, three with $\mathrm{HGH} \mathrm{F}$, and three with $\mathrm{HGH} \mathrm{W}$, the nature of the disappearance curves was essentially the same. Subjects H. B. and D. C. were each studied with two of the HGH preparations and the disappearance curves are shown in Fig. 3.

Fig. 4 compares the disappearance curves when labeled hormone is analyzed by the three techniques described above. It will be seen that the multiexponential nature of the disappearance curve is independent of the analytical procedure employed. The patterns of disappearance of growth hormone, damaged components, and free iodide in a single experiment are shown in Fig. 5. Two points of interest are noted. Firstly, free iodide appears quite rapidly and at the end of $60 \mathrm{~min}$ accounts for the greatest part of the total plasma radioactivity; secondly, the concentration of "damaged" hormone after an initial rapid phase of disappearance declines more slowly than the material at the origin.

Values for MCR calculated from single injection studies are shown in Table I. It is evident that there is good agreement between the results obtained by planimetry and those by computer analysis when the disappearance curves are described by the sum of three exponential functions. These values are significantly lower than when the sum of two exponentials are used to describe the disappearance curves.

Unlabeled HGH. Results obtained when unlabeled HGH was administered are shown in Fig. 6. It is evident that the disappearance curve is again multiexponential in nature as noted above with the labeled material. 
Accurate delineation of the latter part of the curve (120-150 min after injection) was difficult unless unphysiological amounts of HGH were administered. This was due both to spontaneous fluctuations in plasma $\mathrm{HGH}$ levels and to decreased precision of the assay at the plasma concentrations of 1-2 $\mathrm{m} \mu \mathrm{g} / \mathrm{ml}$ encountered at this time.

\section{Constant infusion studies}

When isotopically labeled $\mathrm{HGH}$ was administered by continuous infusion a constant plasma level was obtained at the end of $3 \mathrm{hr}$ and subsequent values remained within $\pm 5 \%$ of the mean. The MCR values calculated from these results are shown in Table I. It will be noted that, in general, the values agree well with those derived from single injection studies when MCR is calculated by planimetry or by describing the disappearance curves by the sum of three exponential functions.
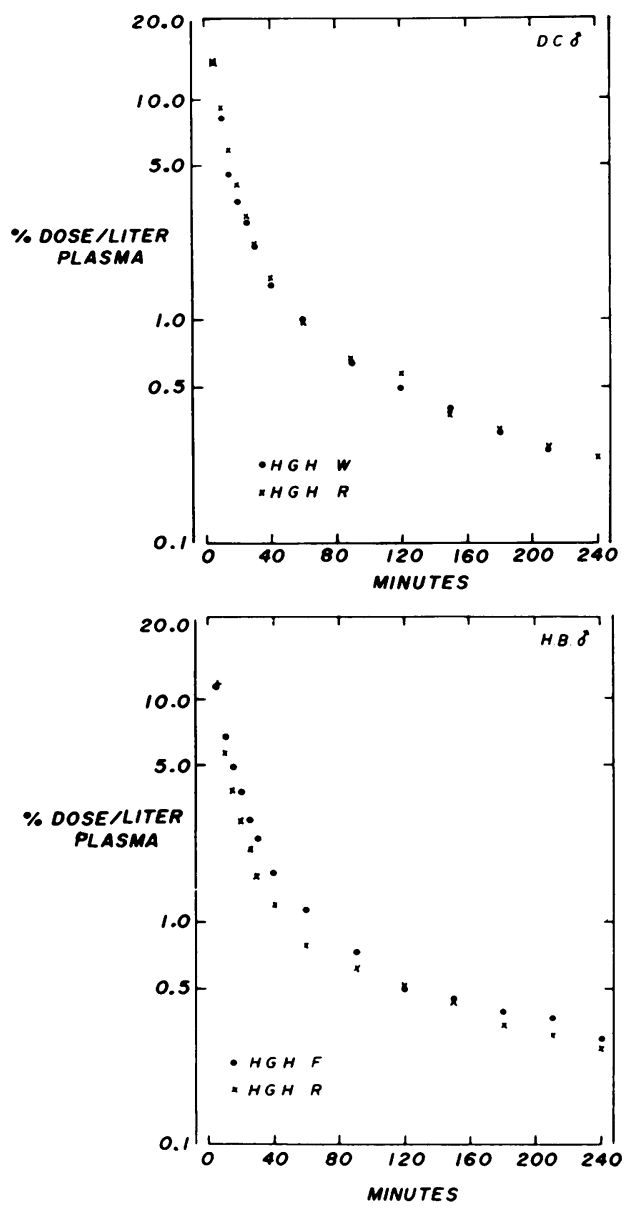

FIgURE 3 Disappearance curves comparing various growth hormone preparations. Above, subject D. C.: comparison of Raben (HGH R) and Wilhelmi ( $\mathrm{HGH} \mathrm{W}$ ) preparations. Below, subject H. B.: comparison of Raben ( $\mathrm{HGH}$ R) and Ferguson (HGH F) preparations.
Recovery of radioactivity from urine. After rapid intravenous injection of labeled hormone, radioactivity appeared in urine as shown in Fig. 7. At the end of $24 \mathrm{hr}$ approximately $75 \%$ of the total administered dose had been recovered and this had increased to $92 \%$ by $72 \mathrm{hr}$. Essentially, none of this radioactivity was immunoprecipitable or remained at the origin during chromatoelectrophoresis. About $2 \%$ of the urinary radioactivity could be precipitated with trichloracetic acid.

\section{DISCUSSION}

Although the measurement of $\mathrm{HGH}$ in plasma is now widely used in the assessment of pituitary function, few reports on the metabolic fate of the hormone or attempts to measure its secretion rate in man have been published.

The present studies were performed with two aims in view. Firstly, it was proposed to examine in more detail the disposal of growth hormone in normal man so that the effects of hormonal and metabolic factors on this could be assessed; secondly, it was hoped that through the measurement of MCR an approach might be made to the estimation of secretion rate.

Disappearance curves. The present finding of a multiexponential disappearance curve for iodinated $\mathrm{HGH}$ is at variance with the conclusions reached as the result of previous investigations. Parker et al. (1) found that, in three subjects, the disappearance curve from $10 \mathrm{~min}$ to $100 \mathrm{~min}$ was described by a single exponential function with half-times $\left(t_{\frac{1}{2}}\right)$ of disappearance from $17 \mathrm{~min}$ to $34 \mathrm{~min}$. Reexamination of these data suggests that at least two of these curves could equally well represent a multiexponential disappearance. Boucher (2) also reported a single exponential disappearance commencing after $20 \mathrm{~min}$ with $\mathrm{a}_{\frac{1}{2}}$ in normal subjects of 23-45 min. Laron, Mannheimer, and Guttman (4), however, found the disappearance curve consisted of three segments. An extremely fast mixing phase was followed by a segment with $t_{\frac{1}{2}} 20-30 \mathrm{~min}$ considered to represent the metabolism of true $\mathrm{HGH}$. Finally, a slow phase with $\mathrm{t}_{\frac{1}{2}}$ of approximately $160 \mathrm{~min}$ was interpreted as the disappearance of iodinated degradation products. Conti et al. (3) reported the disappearance curve to have two phases; the first in the period 10-60 min with $t_{\frac{1}{2}}$ of about $20 \mathrm{~min}$, the second from 1 to $8 \mathrm{hr}$ with $\mathrm{t}_{\frac{1}{2}}$ of $270 \mathrm{~min}$. This group felt that the late slow phase represented metabolism of $\mathrm{HGH}$ whereas the earlier phase was still distributive. When studying pregnant women at term, Gitlin, Kumate, and Morales (17) found that the disappearance of $\mathrm{HGH}$ from plasma could not be represented by a single exponential function until almost 4 $\mathrm{hr}$ had elapsed. As can be seen in Fig. 2, it is necessary to describe the disappearance curve by the sum of at least three exponential functions and this differs from most of the above interpretations. 


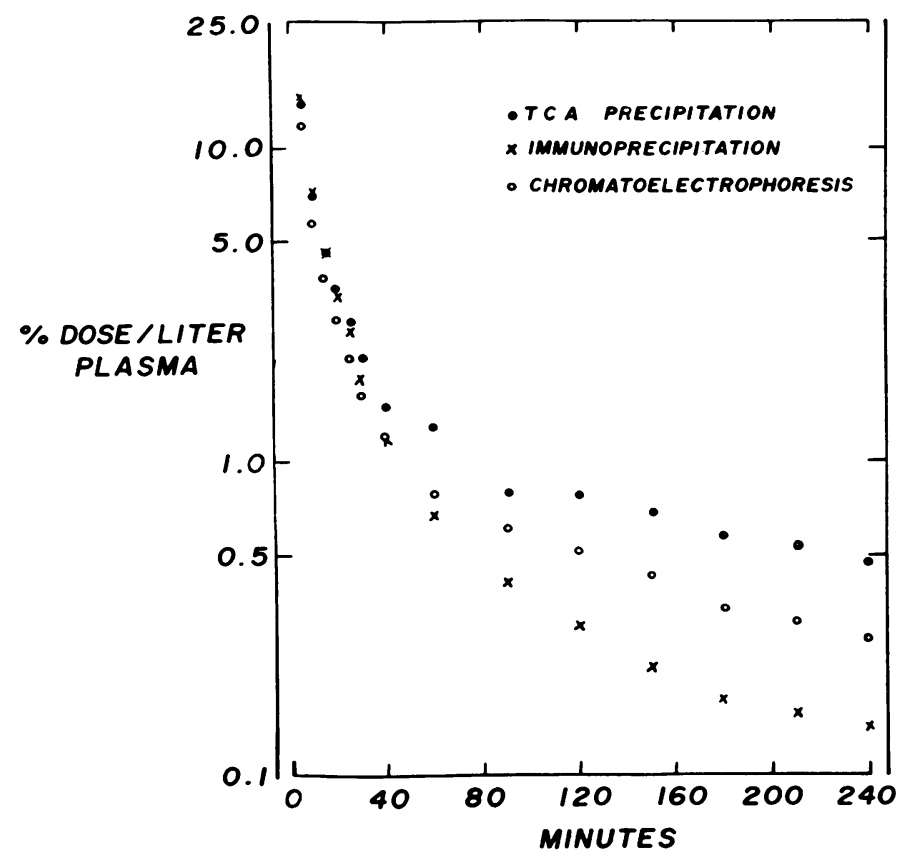

FIGURE 4 Comparison of three different techniques for assessment of radioiodinated $\mathrm{HGH}$ in plasma. It will be noted $(a)$ In each case the curve obtained is multiexponential, and $(b)$ The absolute value of labeled hormone in plasma varies with the method of analysis employed.

With the exception of the data of Boucher (2) it is probable that the discrepancy between the nature of the disappearance curves in these previous reports and those found in present study is largely a reflection of the frequency and duration of sampling. To define a multiexponential system precisely, a sufficient number of points must be obtained for a time long enough to permit accurate construction of the curve. Conversely, the number of exponentials used to describe a disappearance curve of this type will depend on the number and accuracy of the experimental points obtained. The number of compartments defined, the volume of distribution of

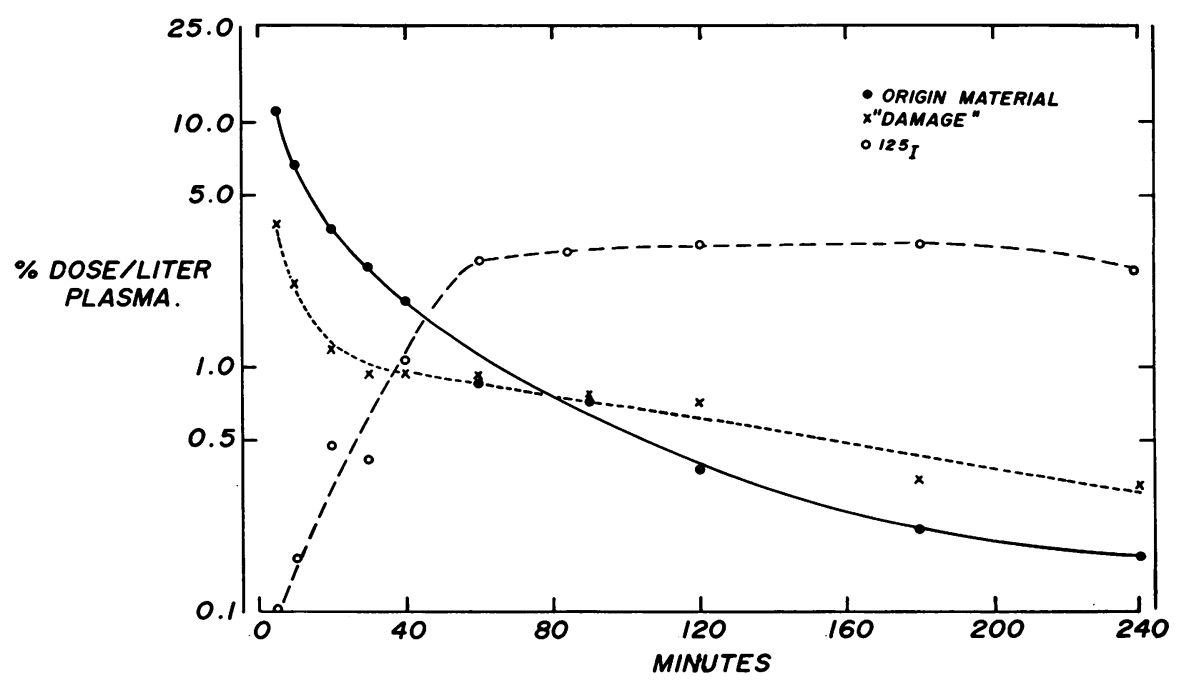

FIGURE 5 Chromatoelectrophoretic analysis of radioiodinated $\mathrm{HGH}$ in plasma. Undamaged hormone is compared with damaged components and with free iodide. 


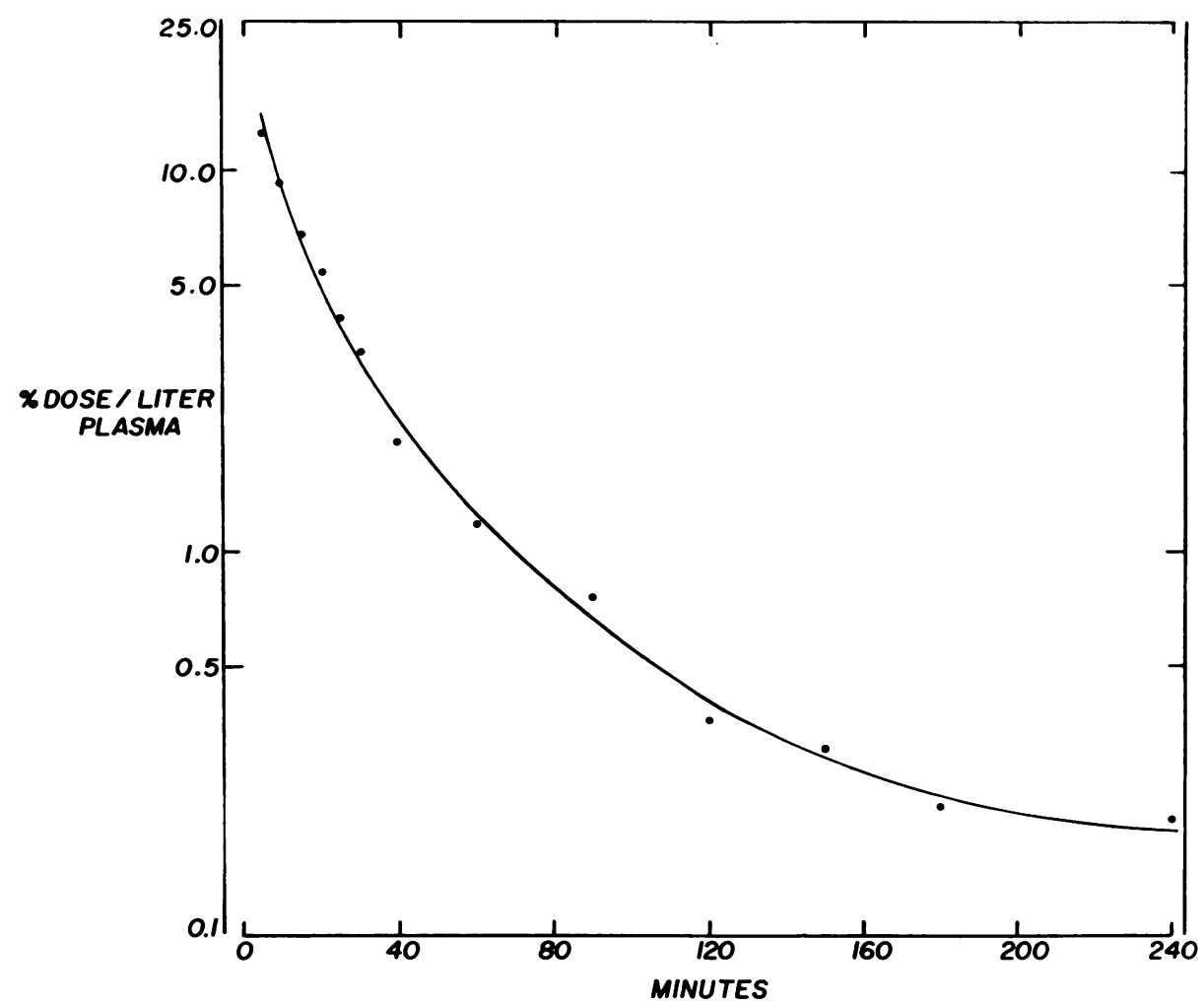

FIgURE 6 Disappearance curve of unlabeled HGH. The points represent the mean of values from five studies. After $120 \mathrm{~min}$, however, they represent the mean of two or three values only. The amount of hormone administered ranged from $300 \mu \mathrm{g}$ to $10 \mathrm{mg}$. Basal plasma levels ranged from 0.5 to $5 \mathrm{~m} \mu \mathrm{g} / \mathrm{ml}$ and values $5 \mathrm{~min}$ after injection were $47-1220$ $\mathrm{m} \mu \mathrm{g} / \mathrm{ml}$.

hormone within them, and the individual rates of disappearance from them will depend on the number of exponentials used to describe the curve and may not correspond to any anatomical or physiological subdivision. Similarly, it would appear speculative in the present state of knowledge to consider any particular segment of the curve as representing the steady-state disappearance of $\mathrm{HGH}$. A similar multiexponential disappearance has been described recently by Kohler, Ross, and Odell (18) for human luteinizing hormone.

Before the results obtained from such studies with iodinated hormone can be extrapolated to events occurring with the naturally secreted product, it should be shown, ideally, that the disappearance of iodinated tracer is the same as for endogenously produced protein. Glick, Roth, and Lonergan (19) reported studies on the disappearance of endogenous $\mathrm{HGH}$ from plasma after the suppression by glucose of growth hormone secretion stimulated by insulin-induced hypoglycemia and after hypophysectomy for acromegaly. The disappearance curves obtained were reported as essentially exponential in nature and $t_{t}$ of disappearance were between 20 and $30 \mathrm{~min}$. Attempts to repeat the former experiments were made in the present study, but HGH suppression was poor and occurred irregularly in spite of elevation of blood sugar levels. However, reexamination of the data given by Glick et al. (19) suggests that similar problems occurred to some extent in their own studies. Further, it appears that several of their disappearance curves could be described more correctly as multiexponential in type though the number of points shown

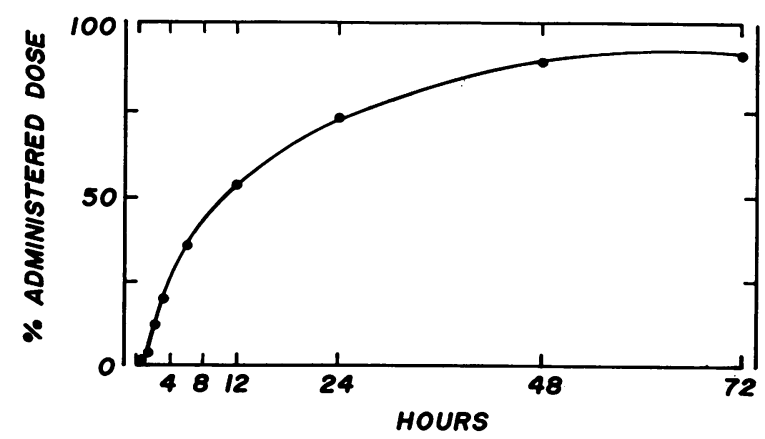

FIGURE 7 Recovery of radioactivity in urine. Cumulative urinary radioactivity after single intravenous injection of radioiodinated $\mathrm{HGH}$ is shown. 
is not sufficient to define the curve with certainty. Either of these approaches is open to the criticism that complete cessation of secretion cannot be guaranteed and thus an erroneously prolonged disappearance curve may be obtained. Further, the relative imprecision of radioimmunoassay procedures at low plasma concentrations makes accurate definition of the latter part of the curve impossible.

Because of the difficulties in making a direct comparison of iodinated tracer with the endogenously produced hormone, careful examination of possible artefacts was undertaken, in regard to the following potential sources of error: $(a)$ the extraction procedure used in preparation of $\mathrm{HGH}$ : as shown above there was no significant difference in the disappearance of growth hormone prepared by three different extraction procedures. (b) Iodination of the hormone: the results obtained with iodinated hormone using a standard iodination procedure agreed well with those for unlabeled HGH. In addition one experiment using $\mathrm{HGH}_{-}{ }^{125} \mathrm{I}$ prepared by diffusion employing a Conway diffusion chamber and analyzed by TCA precipitation gave a disappearance curve identical to those obtained with $\mathrm{HGH}_{-}{ }^{125} \mathrm{I}$ iodinated by the chloramine- $T$ method and analyzed in the same way. (c) The specificity of measurement of iodinated HGH in plasma: the general shape of the disappearance curves obtained after measuring iodinated $\mathrm{HGH}$ by the three methods employed was similar and in agreement with that for the unlabeled hormone. It has been suggested $(1,4)$ that the later, slower part of the disappearance curve may be due to the presence of iodinated degradation products with clearance rates different from that of undamaged hormone. Interference by degradation products would appear more likely with the less specific method of TCA precipitation than with the other two techniques and may account in part for the somewhat higher plasma levels obtained by this method. It is uncertain which of these methods of analysis most closely represents biologically active hormone, though it is perhaps to be expected that the values obtained by immunoprecipitation would correspond best with immunoreactive $\mathrm{HGH}$ as measured by radioimmunoassay.

Metabolic clearance rate. Of the two methods used for estimation of MCR the constant infusion technique is advantageous because it allows simple and accurate calculation of the integrated plasma radioactivity $(14,16)$. After rapid single injection, the calculation of MCR requires integration of the entire disappearance curve. This is most simply performed by measuring the area under the curve by planimetry. Alternatively, the disappearance curve can be described mathematically by the sum of a number of exponential functions $\left(x^{\prime}=A^{\prime} e^{-\alpha t}\right.$ $\left.+\mathrm{B}^{\prime} \mathrm{e}^{-\beta t}+\mathrm{C}^{\prime} \mathrm{e}^{-\gamma t} \ldots\right)$ and $\mathrm{MCR}$ calculated from this equation. However, while these methods are theoretically sound in practice, data to describe the late phase of disappearance may not be available for technical reasons (e.g. low levels of plasma radioactivity). In these circumstances an extrapolation of the tail of the curve must be made, and this extrapolation will be based on the later, less precise experimental points. An error in the extrapolation may affect considerably the calculated value for MCR. Furthermore, in the present study, though the mean data are extremely well described by the sum of three exponential functions (Fig. 2) in the individual case, there is sometimes no significant difference in the closeness of fit by two or three exponential functions. The calculation of MCR based on these two models may, however, vary markedly (Table I). Thus, although the theoretical basis for calculation of MCR after single injection is sound, practical problems in application reduce the reliability of the results obtained in individual studies.

It is of interest to compare the values obtained for MCR or HGH (203 liter/day per $\mathrm{m}^{2}$ ) with the much lower values reported for two other protein hormones: 35 liters/day for human luteinizing hormone (17) and 61 liters/day for thyroid-stimulating hormone (20). Recently, a report has appeared in abstract form (21) in which the MCR for $\mathrm{HGH}$ calculated from constant infusion studies was stated to be 256 liters/day.

Little is known about the sites of clearance of $\mathrm{HGH}$ or the factors which affect the rate of clearance. Salmon, Utiger, Parker, and Reichlin (22) have reported the occurrence of TCA precipitable radioactivity in liver, kidney, and muscle of rabbits given labeled $\mathrm{HGH}$ while other workers (23) have shown by autoradiography that labeled $\mathrm{HGH}$ is concentrated in proximal tubular cells and to a lesser extent in liver parenchymal cells when administered to rats and guinea pigs. Preliminary studies have shown a markedly diminished clearance rate of radioiodinated $\mathrm{HGH}$ in subjects with severe renal failure and a somewhat reduced clearance rate in subjects with liver failure.

The estimation of secretion rate from MCR requires that the level of endogenous hormone in plasma remains constant during the period of observation. It is now known that the level of HGH in plasma fluctuates rapidly throughout the day $(24,25)$ and that a single value or even several values may give an erroneous reflection of average plasma levels. The use of the method of cumulative urinary specific activity (14) which offers advantages in the measurement of secretion rate in these circumstances has not proved feasible due to the difficulty of measuring $\mathrm{HGH}$ in urine.

Frantz and Holub (26) have recently reported mean values for plasma $\mathrm{HGH}$ concentration in males of $0.6-1.5$ $\mathrm{m} \mu \mathrm{g} / \mathrm{ml}$ obtained by use of a constant sampling technique. Thus, using the average value of 203 liters/day 
per $\mathrm{m}^{2}$ for $\mathrm{MCR}$ obtained from the constant infusion studies, secretion rate of $\mathrm{HGH}$ would lie between 120 and $350 \mu \mathrm{g} /$ day per $\mathrm{m}^{2}$. It is of interest that this is less than is usually considered necessary to achieve maximal growth when administered to hypopituitary children.

\section{ACKNOWLEDGMENTS}

We would like to express our appreciation to the following for their help in various aspects of this study: Sister L. M. Anderson, Miss Jennifer Davis, Miss Christine Freestone, Miss Lois Pelchen, and Mr. Paul Pearce.

This study was supported by grants from the National Health and Medical Research Council and the Ian Potter Foundation.

\section{REFERENCES}

1. Parker, M. L., R. D. Utiger, and W. H. Daughaday. 1962. Studies on human growth hormone. II. The physiological disposition and metabolic fate of human growth hormone in man. J. Clin. Invest. 41: 262.

2. Boucher, B. J. 1966. Disappearance of Iodine-131-labelled human growth hormone from the plasma of diabetic, non-diabetic and acromegalic subjects. Nature (London). 210: 1288

3. Conti, C., M. Negri, A. Isidori, O. Recchia, and L. Sereno. 1962. Primi rilievi sul metabolismo dell'STH umano marcato con ${ }^{131}$ I. Folia Endocrinol. (Roma). 15: 721.

4. Laron, Z., S. Mannheimer, and S. Guttman. 1965. Plasma disappearance of various ${ }^{131}$ I-labelled growth hormone preparations in man and rabbit. Nature (London). 207: 298.

5. Brown, J. B., K. J. Catt, and F. I. R. Martin. 1967. Preparation of gonadotrophin and growth hormone from human pituitaries for clinical use. J. Endocrinol. 38: 451.

6. Raben, M. S. 1957. Preparation of growth hormone from pituitaries of man and monkey. Science (Washington). 125: 883.

7. Wallace, A. L. C., and K. A. Ferguson. 1961. Preparation of human growth hormone. J. Endocrinol. 23: 285.

8. Wilhelmi, Alfred E. 1961. Fractionation of human pituitary glands. Can. J. Biochem. Physiol. 39: 1659.

9. Tashjian, J. H., Jr., Lawrence Levine, and Alfred E. Wilhelmi. 1965. Immunochemical relatedness of porcine, bovine, ovine and primate pituitary growth hormone. Endocrinology. 77: 563.

10. Catt, K. J., and J. Culross. 1968. A disposable radioiodination pipet. Anal. Biochem. 26: 207.

11. Greenwood, F. C., W. M. Hunter, and J. S. Glover. 1963.
The preparation of ${ }^{131}$ I-labelled human growth hormone of high specific radioactivity. Biochem. J. 89: 114.

12. Catt, Kevin, H. D. Niall, and G. W. Tregear. 1967. A solid-phase disc radioimmunoassay for human growth hormone. J. Lab. Clin. Med. 70: 820.

13. Catt, Kevin, and G. W. Tregear. 1967. Solid-phase radioimmunoassay in antibody-coated tubes. Science (Washington). 158: 1570 .

14. Tait, J. F., and S. Burstein. 1964. In vivo studies of steroid dynamics in man. In The Hormones. G. Pincus, K. V. Thimann, and E. B. Astwood, editors. Academic Press Inc., New York. 5: 441.

15. Berman, M., E. Shahn, and M. F. Weiss. 1962. The routine fitting of kinetic data to models: a mathematical formalism for digital computers. Biophys. J. 2: 275.

16. Tait, J. F. 1963. Review: The use of isotopic steroids for the measurement of production rates in vivo. J. Clin. Endocrinol. Metab. 23: 1285.

17. Gitlin, D., J. Kumate, and C. Morales. 1965. Metabolism and maternofetal transfer of human growth hormone in the pregnant woman at term. J. Clin. Endocrinol. Metab. 25: 1599 .

18. Kohler, P. O., G. T. Ross, and W. D. Odell. 1968. Metabolic clearance and production rates of human luteinizing hormone in pre and postmenopausal women. J. Clin. Invest. $47: 38$

19. Glick, S. M., J. Roth, and E. T. Lonergan. 1964. Survival of endogenous human growth hormone in plasma. J. Clin. Endocrinol. Metab. 24: 501.

20. Odell, W. D., R. D. Utiger, J. F. Wilber, and P. G. Condliffe. 1967. Estimation of the secretion rate of thyrotropin in man. J. Clin. Invest. 46: 953.

21. Finster, J. L., A. L. Taylor, and D. H. Mintz. 1968. Metabolic clearance and production rates of human growth hormone. J. Clin. Invest. 47: 35a (Abstr.)

22. Salmon, S., R. D. Utiger, M. L. Parker, and S. Reichlin. 1962. The fate of ${ }^{131}$ I labeled human growth hormone in the rahbit. Endocrinology. 70: 459.

23. Collipp, P. J., J. R. Patrick, C. Goodheart, and S. A. Kaplan. 1966. Distribution of Tritium labeled human growth hormone in rats and guinea pigs. Proc. Soc. Exp. Biol. Med. 121: 173.

24. Hunter, W. M., J. A. R. Friend, and J. A. Strong. 1966. The diurnal pattern of plasma growth hormone concentration in adults. J. Endocrinol. 34: 139.

25. Quabbe, H. J., E. Schilling, and H. Helge. 1966. Pattern of growth hormone secretion during a 24 hour fast in normal adults. J. Clin. Endocrinol. Metab. 26: 1173.

26. Frantz, A. G., and D. A. Holub. 1968. Daily secretion rates of human growth hormone ( $\mathrm{HGH}$ ) based on a new technique for continuous blood sampling. Excerpta Med. Int. Congr. Ser. No. 157: 18. (Abstr. 44). 